\title{
Laryngeal granulomas in patients after two-jaw surgery \\ - Four cases report -
}

Received April 11, 2019

Revised 1st, May 23, 2019

2nd, July 10, 2019

Accepted July 12, 2019

\section{Corresponding author}

Seok Kon Kim, M.D., Ph.D.

Department of Anesthesiology and Pain Medicine, Dankook University College of Medicine, 119 Dandaero, Dongnam-gu, Cheonan 31116, Korea

Tel: 82-41-550-6819

Fax: 82-41-550-6819

E-mail:skkim@dankook.ac.kr ORCID

https://orcid.org/0000-0003-1762-2052

\section{Jae Gyok Song, Won Ho Cho, Sung Mi Ji, Jeong Heon Park, and Seok Kon Kim}

Department of Anesthesiology and Pain Medicine, Dankook University Hospital, Dankook University College of Medicine, Cheonan, Korea

Background: Endotracheal intubation can cause focal ischemia, damage or edema to the laryngeal mucosa, and may be followed by serious complications such as vocal cord paralysis, ulcers, and granulation tissue formation. Laryngeal granuloma is rare but also a significant late complication of endotracheal intubation, and anesthesiologists should be concerned about it.

Case: We experienced four cases of laryngeal granuloma that developed after two-jaw surgery January 2017-December 2018 in our hospital and would like to report these cases with brief review of literature.

Conclusions: There are frequent movements on the head and neck in maxillofacial surgery and the nasotracheal intubation should be prolonged after bimaxillary osteotomy surgery because of post-operative airway problems. This may be why two-jaw surgery may have higher occurrence of laryngeal granuloma than others.

Keywords: Endotracheal intubation; Laryngeal granuloma; Maxillofacial surgery.

Laryngeal granuloma is an inflammatory reaction caused by direct trauma of perichondrium of arytenoid cartilage and mucosa. There are several causes of laryngeal granuloma including endotracheal intubation, gastroesophageal or laryngopharyngeal reflux, trauma, and idiopathic origin [1]. Endotracheal intubation can cause focal ischemia, damage or edema to the laryngeal mucosa, and may be followed by serious complications such as vocal cord paralysis, ulcers, and granulation tissues [2]. Also, endotracheal intubation accounts for a major part (22.7\%) among causes of laryngeal granuloma [3]. In our practice, two-jaw surgery has higher risk of vocal cord injury due to frequent movement of the head and/or neck for manipulation, and prolonged duration of nasotracheal intubation. Anesthesiologists should clearly understand etiology, risk factor, diagnosis, and treatment of post-intubation laryngeal granuloma to minimize incidence. Also, early diagnosis and treatment will facilitate prevention of serious complications such as fatal airway obstruction as well as reduce medical costs. We experienced four cases of laryngeal granuloma after two-jaw surgery January 2017-December 2018 in our hospital and it was of relatively higher incidence than we expected in clinical practice. Then we would like to report these cases with the patients' consent received about publishing all photographic materials.

\section{CASE REPORTS}

\section{Case 1}

An age 17 female, $167 \mathrm{~cm}$ tall, weighing $43 \mathrm{~kg}$, was sched-

This is an Open Access article distributed under the terms of the Creative Commons Attribution Non-Commercial License (http://creativecommons.org/licenses/by-nc/4.0) which permits unrestricted non-commercial use, distribution, and reproduction in any medium, provided the original work is properly cited. 
uled for two-jaw surgery due to mandibular prognathism. Her medical history and pre-operative evaluations were unremarkable. After standard monitoring and preoxygenation, general anesthesia was induced with intravenous lidocaine $30 \mathrm{mg}$, propofol $70 \mathrm{mg}$, fentanyl $25 \mu \mathrm{g}$, and rocuronium 30 $\mathrm{mg}$. Following mask ventilation for three minutes with $100 \%$ oxygen and 4 vol\% sevoflurane, we inserted an internal diameter of 6.5-mm Polar ${ }^{\mathrm{TM}}$ Preformed Tracheal Tube (Smith Medical, USA) via nasal airway under direct laryngoscopy. We successfully intubated the patient on the first attempt and there was no specific problem during intubation. General anesthesia was maintained with 2-3 vol\% sevoflurane and intermittent dose of rocuronium and fentanyl. Upon completion of surgery, residual muscle relaxation was reversed with atropine and neostigmine. Post-operative pain control started via patient-controlled analgesia (PCA) with fentanyl and ketamine infusion. Surgery was successfully completed by total operation duration of three hours, $35 \mathrm{~min}$ and total anesthesia duration of four hours, $20 \mathrm{~min}$. The patient was transferred to intensive care unit (ICU) maintaining nasotracheal intubation with spontaneous ventilation. Antibiotics and oral gargling was administered in ICU and on the second post-operative day (POD2) she was extubated. Total intubation duration was $53 \mathrm{~h}$ and on the fifth day after extubation, she was discharged without complications.

One month after discharge, she experienced voice change and did not improve so she visited the otolaryngology clinic three months after the surgery. Laryngoscopic exam showed laryngeal granuloma (Fig. 1A) and conservative treatment was performed for two months. However, it was not effective and laryngoscopic microscopic surgery was performed to remove laryngeal granuloma. The symptom was relived after surgery (Fig. 1B).

\section{Case 2}

An age 28 female, $154 \mathrm{~cm}$ tall, weighing $59 \mathrm{~kg}$, with no specific medical history underwent two-jaw surgery due to facial asymmetry. General anesthesia was induced with intravenous lidocaine $40 \mathrm{mg}$, propofol $100 \mathrm{mg}$, remifentanil 0.05 $\mu \mathrm{g} / \mathrm{kg} / \mathrm{min}$ infusion and rocuronium $40 \mathrm{mg}$ with standard monitoring and preoxygenation. Nasotracheal intubation was performed under direct laryngoscopy with an internal diameter of 6.5-mm Polar ${ }^{\mathrm{TM}}$ Preformed Tracheal Tube (Smith Medical). We successfully intubated the patient on the first attempt and there was no specific problem during intubation. General anesthesia was maintained with 7-9 vol\% desflurane and intermittent doses of rocuronium. At the end of surgery, residual muscle relaxation was reversed and postoperative pain control started via PCA with fentanyl and ketamine infusion. Total operation duration was four hours and total anesthesia duration was four hours, $35 \mathrm{~min}$. The patient was transferred to ICU maintaining nasotracheal intubation. She was extubated on POD3 and total intubation duration was $72 \mathrm{~h}$. Five days after extubation, the patient was discharged without complaints.

One month later, the patient complained voice change and vocal cord granuloma was observed by laryngeal examination (Fig. 2A). Conservative treatment was performed and after two weeks, symptoms disappeared and laryngeal examination showed decreased size of the granuloma (Fig. 2B).

\section{Case 3}

An age 19 female, $159 \mathrm{~cm}$ tall, weighing $53 \mathrm{~kg}$, was scheduled for two-jaw surgery because of facial asymmetry and treated with similar anesthetic and surgical procedures. Total operation duration was three hours, $10 \mathrm{~min}$, and anesthesia

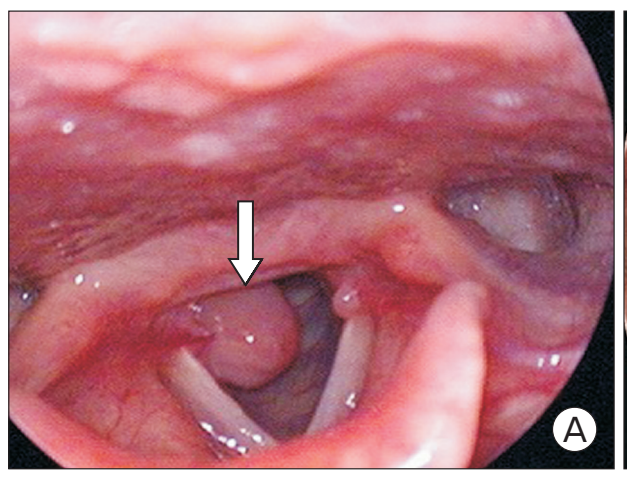

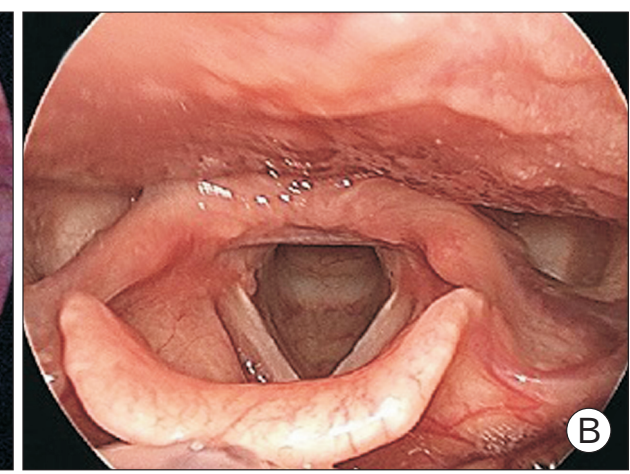

Fig. 1. (A) Laryngoscopic view shows larger right-sided vocal cord granuloma (arrow) than left at three months after two-jaw surgery. (B) After laryngomicroscopic surgery the granuloma is removed. 

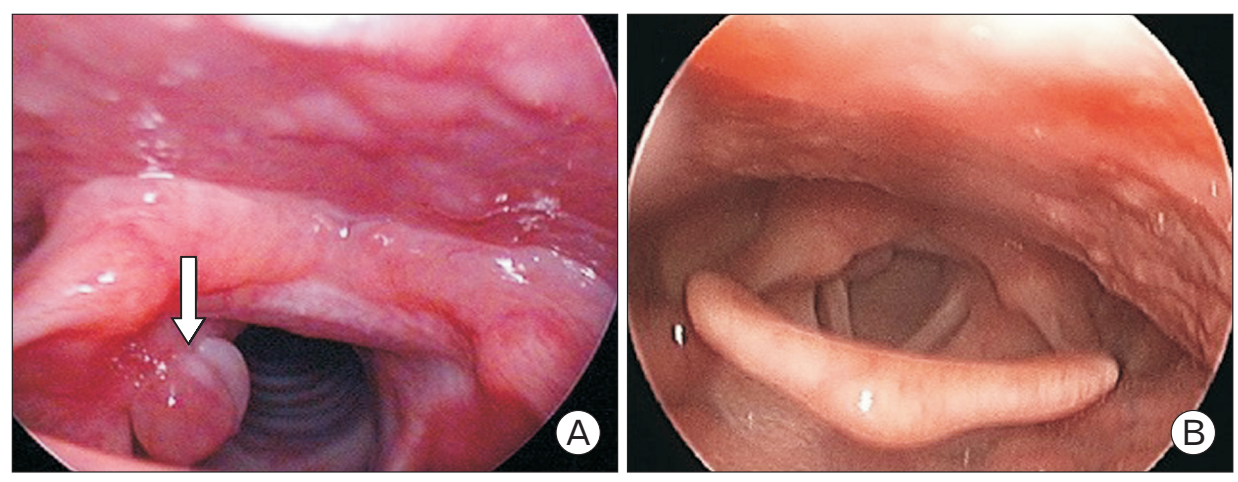

Fig. 2. (A) Laryngoscopic view shows right-sided vocal cord granuloma (arrow) one month after two-jaw surgery. (B) The granuloma decreases after conservative treatments for two weeks.
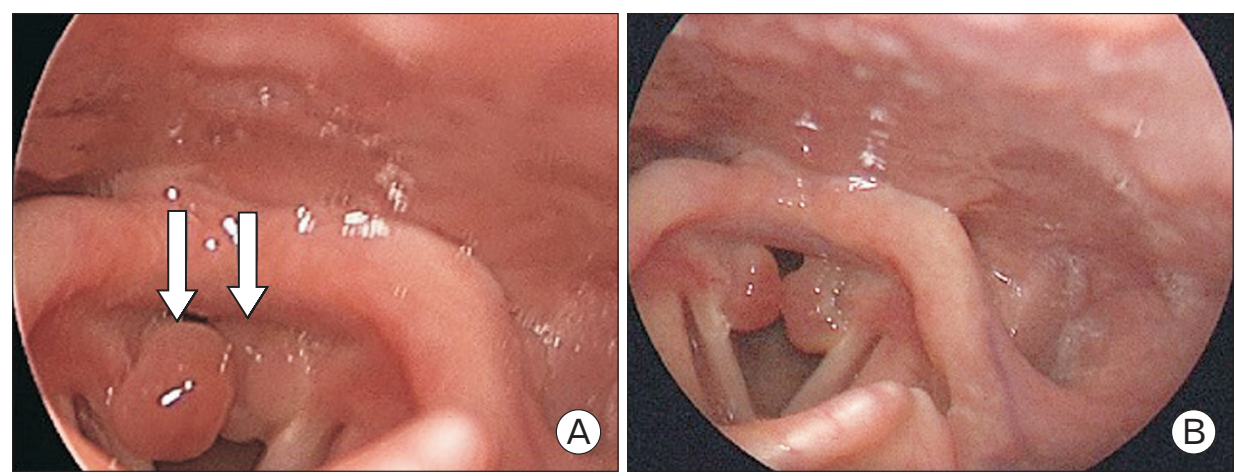

Fig. 3. (A) Laryngoscopic view shows vocal cord granuloma at both sides (arrows) four months after surgery. (B) The granuloma size decreases after conservative treatments for two months.
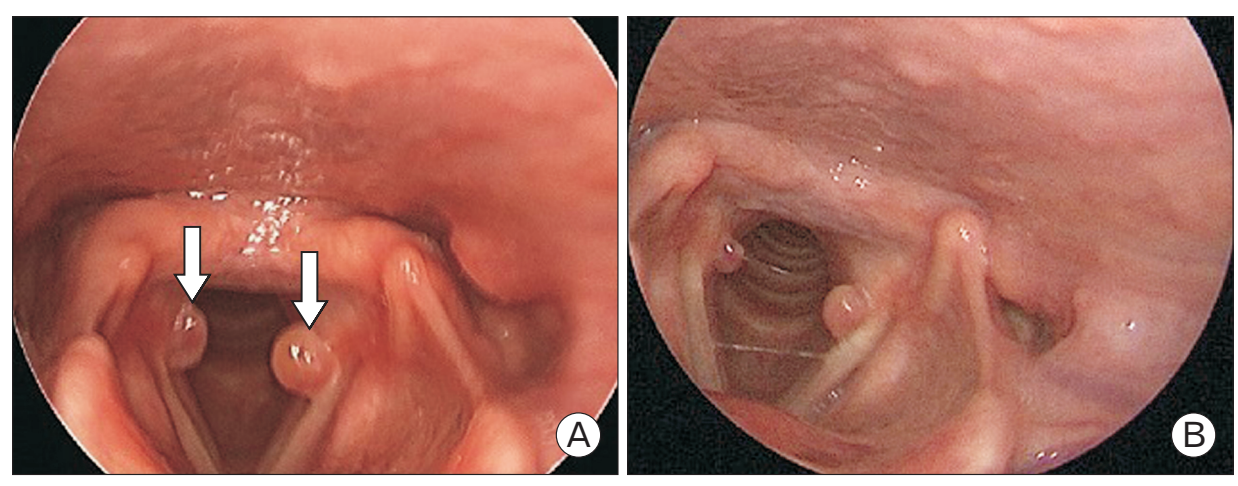

Fig. 4. (A) Laryngoscopic view shows vocal cord granuloma at both sides (arrows) five months after surgery. (B) The granuloma decreases after conservative treatment for one month.

duration was four hours. She was also treated with same postoperative ICU care with keeping endotracheal tube and total intubation duration was $49 \mathrm{~h}$. Two months later, she experienced voice change and received two months of conservative treatment. However, the symptom persisted, so she visited the otolaryngology clinic and laryngeal examination showed vocal cord granulomas (Fig. 3A). Then she had conservative treatment for two months. After treatment, granuloma size and symptoms decreased (Fig. 3B).

\section{Case 4}

An age 25 male, $178 \mathrm{~cm}$ tall, weighing $88 \mathrm{~kg}$, was scheduled for two-jaw surgery to treat facial asymmetry. The patient was treated with similar anesthetic with 7.0-mm Polar ${ }^{\mathrm{TM}}$ Preformed Tracheal Tube and surgical procedures. Total anesthesia duration was four hours, $30 \mathrm{~min}$, and total intubation duration was 44 h, $30 \mathrm{~min}$. Five months after surgery, he visited the otolaryngology due to voice change and laryngoscopic examination showed laryngeal granulomas (Fig. 4A). He received conservative treatment, and the symptom and granuloma size decreased (Fig. 4B).

\section{DISCUSSION}

Laryngeal granuloma was first reported by Clausen in 1932 
[4]. Since then, many cases of laryngeal granuloma have been reported as a serious complication after endotracheal intubation due to increased general anesthesia. It is rare but also a significant late complication of endotracheal intubation and anesthesiologists should be concerned about it. Anesthesiologists should understand risk factor, symptom, diagnosis, and treatment of post-intubation laryngeal granulation to minimize occurrence and prevent serious complications such as fatal airway obstruction.

Age, gender, and anatomic abnormality are key factors that can cause post-intubation laryngeal granuloma and obese adult females with short neck or airway abnormality are more vulnerable [5]. It is reported that high risk factors of laryngeal trauma and granulation include long intubation duration of more than $24 \mathrm{~h}$ and trauma to the larynx via various mechanisms such as traumatic intubation, need for re-intubation, tube exchanges increased movement while intubated, and presence of respiratory tract infection during intubation [6]. Females have higher prevalence of post-intubation laryngeal granuloma because of less resistance to laryngeal epithelium trauma and higher odds of using an oversized endotracheal tube [5]. In our case, we observed that three cases were females, and maintenance of endotracheal intubation for 44-72 h, including anesthesia for surgery and post-operative care, could be predisposing factors of laryngeal granulation.

Laryngeal granuloma can be asymptomatic and usually heals spontaneously without special treatment if small. There is a report that laryngeal granuloma without previous symptoms was incidentally detected during endotracheal intubation in a woman who had been intubated five days for subarachnoid hemorrhage [7]. That's why we usually do not take this issue seriously. But vocal cord granuloma can cause dysphonia, hoarseness, sensation of a strange body inside the throat. Worsening conditions can cause difficulty with breathing, even fatal unconsciousness [8].

Rigid or flexible laryngoscopy have been used for diagnosis of laryngeal granuloma in patients with voice change or sensation of a foreign body in the neck. The most important treatment for laryngeal granuloma is conservative including voice rest, voice therapy, and medication (proton pump inhibitor, PPI and/or steroid). Eighty-six percent of laryngeal granuloma patients were resolved with conservative treatment [9]. Surgical removal may be considered in patients not responding to conservative therapies or with airway obstruc- tion [10]. In three patients regarding our cases, symptoms improved and granuloma size decreased with conservative treatments including voice rest and medications. One case needed surgical removal of laryngeal granuloma due to persistent symptoms and granuloma despite conservative treatment for more than one month. She experienced voice change for one month after surgery, and eventually fully recovered after surgery. The patient first visited the otolaryngology clinic two months after she initially experienced symptoms. If she had been informed about the risk of laryngeal granulation, she could have been admitted to hospital earlier for treatment.

Due to the nature of two-jaw surgery, surgeons must move the patient's head and neck many times during surgery. Although an atraumatic nasal intubation is performed during anesthesia, movement of the ballooned endotracheal tube may cause damage to the vocal cord, which would be a risk factor for laryngeal granulation. Thus, the anesthesiologist and surgeon should maintain pressure of the endotracheal tube cuff properly between $20-30 \mathrm{cmH}_{2} \mathrm{O}$ and restrict head and neck movement during surgery. Use of unsuitable size tubes for patients may also be a risk factor for laryngeal granulation. However we used $6.5 \mathrm{~mm}$ tubes for females and 7.0 $\mathrm{mm}$ tubes for males and these were not oversized to increase additional injury risks. There are reports that nasotracheal intubation provides lesser laryngeal injury for the long-term intubation state and more stability during head and neck surgery than orotracheal intubation [11].

Bimaxillary osteotomy surgery usually performed for facial deformity or cosmetic purpose may have many postoperative functional complications such as bleeding, nerve injury, neuropathic pain, nasal and temporomandibular disorder, and even respiratory insufficiency [12]. Post-operative aspiration pneumonia due to bleeding and secretion can occur in approximately $0.01-0.06 \%$ [13]. Dyspnea also can develop due to narrowing of the airway from post-operative edematous change or posterior movement of the mandible by bilateral sagittal split ramus osteotomy [14]. For this reason, in our practice we retained the nasotracheal tube for at least two post-operative days when orofacial edematous change decreased after removal of nasal packing and patients could cooperate with breathing effort and expectoration sufficiently. This long-term maintenance of the tube may have contributed to laryngeal granulation. 
It is reported that incidence of laryngeal granulation after endotracheal intubation is $0.017-0.05 \%$ [15]. But incidence of vocal cord granulation in patients who had two-jaw surgery in out hospital showed approximately $8.7 \%$ January 2017 December 2018. It was significantly higher occurrence rate than we expected. Although our disappointing result may not be explained with obvious causes, contributing factors can be considered such as females in preference for two-jaw surgery, frequent movement of the endotracheal tube perioperatively, and inadequate management including pain control or sedation in the intensive care unit, as well as prolonged duration of intubation. Thus, we should deeply care about pre-operative patient education, atraumatic intubation skill, minimizing peri-operative manipulation of endotracheal tube movement, appropriate post-operative calmness, reducing the duration of nasotracheal intubation by comparing its risks and benefits, and practicing a multidisciplinary approach relative to surgeons and anesthesiologists.

In conclusion, we should do our best to reduce causes of laryngeal granulation. Especially, bimaxillary osteotomy surgery requires atraumatic intubation as far as possible, and appropriate tube size and cuff pressure. Laryngeal damage should be minimized by restricting movement of the head and neck during surgery. Additionally, laryngeal granulation can be reduced by decreasing duration of intubation through considering benefits and risks of prolonged nasotracheal intubation for post-operative care. Finally, for preventing a serious situation, patients with high risk factors of laryngeal granuloma should be educated to promptly visit the hospital if symptoms develop.

\section{CONFLICTS OF INTEREST}

No potential conflict of interest relevant to this article was reported.

\section{ORCID}

Jae Gyok Song: https://orcid.org/0000-0002-4727-6296

Won Ho Cho: https://orcid.org/0000-0003-1828-5430

Sung Mi Ji: https://orcid.org/0000-0002-9633-8086

Jeong Heon Park: https://orcid.org/0000-0003-3852-5390

\section{REFERENCES}

1. Lemos EM, Sennes LU, Imamura R, Tsuji DH. Vocal process granuloma: clinical characterization, treatment and evolution. Braz J Otorhinolaryngol 2005; 71: 494-8.

2. Hamdan AL, Sabra O, Rameh C, El-Khatib M. Persistant dysphonia following endotracheal intubation. Middle East J Anaesthesiol 2007; 19: 5-13.

3. de Lima Pontes PA, De Biase NG, Gadelha EC. Clinical evolution of laryngeal granulomas: treatment and prognosis. Laryngoscope 1999; 109(2 Pt 1): 289-94.

4. Clausen RJ. Unusual sequela of tracheal intubation. Proc R Soc Med 1932; 25: 1507.

5. Blanc VF, Tremblay NA. The complications of tracheal intubation: a new classification with a review of the literature. Anesth Analg 1974; 53: 202-13.

6. Jang M, Basa K, Levi J. Risk factors for laryngeal trauma and granuloma formation in pediatric intubations. Int J Pediatr Otorhinolaryngol 2018; 107: 45-52.

7. Kim HK, Woo NS, Jeong SM, Kwon WK. Incidentally detected laryngeal granuloma during orotracheal intubation under direct laryngoscope: a case report. Anesth Pain Med 2010; 5: 92-4.

8. Park SY, Choi HS, Yoon JY, Kim EJ, Yoon JU, Kim HY, et al. Fatal vocal cord granuloma after orthognathic surgery. J Dent Anesth Pain Med 2018; 18: 375-8.

9. Rimoli CF, Martins RHG, Catâneo DC, Imamura R, Catâneo AJM. Treatment of post-intubation laryngeal granulomas: systematic review and proportional meta-analysis. Braz J Otorhinolaryngol 2018; 84: 781-9.

10. Karkos PD, George M, Van Der Veen J, Atkinson H, Dwivedi RC, Kim D, et al. Vocal process granulomas: a systematic review of treatment. Ann Otol Rhinol Laryngol 2014; 123: 314-20.

11. Dubick MN, Wright BD. Comparison of laryngeal pathology following long-term oral and nasal endotracheal intubations. Anesth Analg 1978; 57: 663-8.

12. Kim YK. Complications associated with orthognathic surgery. J Korean Assoc Oral Maxillofac Surg 2017; 43: 3-15.

13. Kim T, Kim JY, Woo YC, Park SG, Baek CW, Kang H. Pneumomediastinum and pneumothorax after orthognathic surgery -a case report-. Korean J Anesthesiol 2010; 59 Suppl: S242-5.

14. Choi SK, Yoon JE, Cho JW, Kim JW, Kim SJ, Kim MR. Changes of the Airway space and the position of hyoid bone after mandibular set back surgery using bilateral sagittal split ramus osteotomy technique. Maxillofac Plast Reconstr Surg 2014; 36: 185-91.

15. Kim BY, Kong MH, Lim HJ, Chang SH, Chae BK. Clinical observation in 20 cases with intubation granuloma. Korean J Anesthesiol 1994; 27: 251-4. 